\title{
As escalas local e global apresentadas em teses e dissertações brasileiras de educação ambiental
}

\section{The local and global scales of environmental education presented in Brazilian theses and dissertations}

\author{
Glaucia de Medeiros Dias $^{1}$ • Dalva Maria Bianchini Bonotto ${ }^{1}$
}

\begin{abstract}
Resumo: Partindo da perspectiva de que as reflexões sobre os problemas ambientais, bem como sobre as possibilidades de enfrentamento dos mesmos devem considerar a relação inerente entre as escalas local e global referentes a esses problemas, interessou-nos mapear e discutir a produção acadêmica voltada para estas escalas em trabalhos de educação ambiental (EA), a partir de teses e dissertações constantes no Banco de Teses da CAPES, um relevante instrumento de divulgação do conhecimento científico brasileiro. Identificou-se um número considerável de trabalhos acadêmicos que apresentam referências a essas escalas, especialmente a local. Porém, o modo como a maioria dessas menções é feita pode ser caracterizado como difuso e desarticulado, o que pode comprometer as contribuições da EA para o enfrentamento da crise ambiental vigente. Isto aponta para a necessidade de novos esforços que possam elucidar e efetivar as articulações entre as escalas local, global e EA.
\end{abstract}

Palavras-chave: Educação ambiental. Produção científica. Banco de teses da Capes. Escala local. Escala global.

\begin{abstract}
Whereas the debates on environmental issues, as well as on the possibilities of coping with them should consider the inherent relationship between the local and global scales, we became interested in mapping and discussing academic work with regard to these scales in environmental education (EE) from theses and dissertations in the CAPES Theses Database, an important tool for the dissemination of Brazilian scientific knowledge. We identified a considerable number of academic papers that refers to these scales, especially to the local. But the way that many of these references are written can be characterized as diffuse and inarticulate, which we believe can undermine the contributions of EE in the face this current environmental crisis. This indicates the need for further efforts that might elucidate and implement the links between local and global scales and EE.
\end{abstract}

Keywords: Environmental education. Scientific production. CAPES Theses Database. Local scale. Global scale.

\footnotetext{
${ }^{1}$ Programa de Pós-Graduação em Educação, Instituto de Biociências, UNESP - Univ Estadual Paulista, Avenida 24 A, n. 1515, Caixa postal 199, CEP 13506-900, Rio Claro, SP, Brasil. E-mail: <gmedeirosdias@gmail.com>
} 


\section{Introdução}

Apesar de os diferentes segmentos da população, no geral, reconhecerem a gravidade do quadro da degradação ambiental vigente, bem como a necessidade de adotarmos medidas para, pelo menos, contê-lo, não se observa um consenso a respeito de quais medidas devem ser adotadas para tal enfrentamento. A esta constatação, Carvalho (2006) atribui o nome de "consenso aparente", o qual reflete a existência de diferentes visões sobre as causas de origem e manutenção da degradação ambiental e os caminhos a serem percorridos para contorná-la.

Ao refletirmos sobre essas causas, concordamos com os vários autores (GRÜN, 1994; MORIN, 2001; SANTOS, 1998) que defendem que o paradigma civilizatório vigente, caracterizado pelo modelo de racionalidade instrumental, mecanicista, quantitativo e simplificador, é um determinante do atual padrão de relacionamento sociedade-natureza e, consequentemente, da crise ambiental.

Dessa forma, partimos da perspectiva de que os problemas ambientais refletem o contexto histórico no qual estão inseridos. Convém, portanto, fazermos algumas considerações a respeito do fenômeno da globalização, que possui fundamental importância na compreensão da situação vigente.

O processo de globalização, segundo Porto-Gonçalves (2007, p. 1), foi iniciado no ano de 1492, por ocasião das grandes navegações, enquanto o "segundo movimento" deste processo se desenhou a partir do século XVIII, relacionando-se com os caminhos que culminaram na Revolução Industrial. Já o "terceiro movimento", em vigência, teria sido delineado nos últimos 30/40 anos, período no qual a preocupação com o ambiente é parte constitutiva, embora estejamos assistindo a um processo de devastação jamais visto. Em suma, estes três movimentos possuem, em comum, a colonialidade, caracterizada pelo domínio sobre o outro ou sobre a natureza, resultando, pois, em acentuadas desigualdades.

Neste atual movimento da globalização, os "limites da relação da racionalidade eurocêntrica e sua tecnociência, como parte das suas relações sociais e de poder, com a natureza e com outras matrizes de racionalidade começam a ser atingidos" (PORTO-GONÇALVES, 2007, p. 26). No entanto, o autor destaca que, em meio a essa limitação, surge um pensamento ambiental - forjado pelos movimentos sociais, com diversos nomes - que caminha com a natureza e se alimenta do conhecimento do lugar. Com isso, o pensamento local chama-nos a atenção por despontar como uma possibilidade de enfrentamento das desigualdades geradas pela colonialidade, característica do processo de globalização.

A globalização, segundo Giddens (1994), não é apenas um fenômeno econômico, mas é, também, a transformação dos contextos da experiência social, que faz com que atividades cotidianas sejam afetadas por ocorrências que se passam do outro lado do mundo, e, de maneira recíproca, que os hábitos locais tenham consequências globais. Dentro dessa expectativa, Gaskell e Ogawa (2004) afirmam que o local e o global convivem diária e intrinsecamente nas sociedades atuais.

Indo ao encontro dessas ideias, Jacobi (2005, p. 240) aponta que, com “o impacto da globalização, as transformações do cotidiano e o surgimento da sociedade pós-tradicional se caracterizam pela sua instantaneidade, embora contraditória, que inter-relaciona o global e o local", ressaltando que "a sociedade global não é a mera extensão quantitativa e qualitativa da sociedade nacional", todavia, "se constitui como uma realidade original, desconhecida, carente 
de interpretações" (JACOBI, 2005, p. 147), o que passa a exigir profundas reflexões sobre sua constituição e sobre os seus reflexos na vida da sociedade.

Convém destacar que existe discordância sobre a extensão precisa de qualquer escala. Dessa forma, de acordo com interesses particulares e políticos, temos diferentes respostas para a pergunta "quais são os limites do que deve ser considerado local?", o que evidencia o modo como a escala é socialmente construída. Levar esse fato em consideração é uma forma de guiar a compreensão sobre os problemas ambientais globais (CASH; MOSER, 2000).

Esclarecemos que a presente tentativa de mostrar a complexidade das relações que se estabelecem entre as escalas local e global parte da nossa busca por superar uma possível compreensão dicotômica do fenômeno em pauta.

Cash e Moser (2000) explicitam ainda que as mudanças ambientais globais atravessam todas as escalas, requerendo, assim, que todas elas sejam avaliadas e integradas, no intento de tornar as tomadas de decisão, inclusive políticas, mais efetivas. Os autores exemplificam tal afirmação remetendo-se ao problema ambiental global da mudança climática. Segundo eles, a comunidade científica tem aumentado seu interesse em obter dados sobre este problema na escala local, para poder aumentar a precisão dos modelos climáticos globais. Inversamente, os cientistas buscam, também, identificar os impactos locais de tal mudança e, com isso, produzir informações politicamente relevantes, que possam ser utilizadas local e regionalmente.

Ao tratar do fenômeno da globalização, Santos (2002) nos oferece reflexões importantes para pensarmos, sobretudo, as questões ambientais. Para o estudioso, no intento de refletirmos sobre a sociedade global de modo a fugirmos à crença de que esse mundo, como nos é apresentado, é verdadeiro, devemos considerar a existência de três mundos em um só: "o mundo tal como nos fazem vê-lo: globalização como fábula"; "o mundo tal como ele é: globalização como perversidade; e "o mundo como ele pode ser: uma outra globalização" (SANTOS, 2002, p. 9).

Assim, a repetição da ideia de que vivemos em uma aldeia global, por exemplo, faz nos crer que a difusão instantânea de notícias realmente informa as pessoas. Essa ideia, somada ao mito do encurtamento das distâncias, apresenta o mercado, dito global, como capaz de homogeneizar o planeta, embora, na verdade, observe-se que as diferenças locais são profundas e que o mundo se torna menos unido. Consequentemente, o sonho de uma cidadania verdadeiramente universal torna-se mais distante.

A globalização impõe-se como perversa para grande parte da humanidade, que vive: o desemprego crescente, o aumento da pobreza, perda em qualidade de vida da classe média, aparecimento de novas doenças, retorno de doenças supostamente extirpadas, permanência da mortalidade infantil, educação de qualidade cada vez mais inacessível, e o alastramento de males espirituais e morais, como os egoísmos e a corrupção.

O autor vislumbra ainda que essas mesmas bases técnicas, sobre as quais o grande capital se apoia para construir essa globalização perversa, poderão servir a outros objetivos, desde que utilizadas por outros fundamentos sociais e políticos. Nesse ponto, trabalha-se, então, na construção de outra globalização, mais humana. Santos (2002) vai além, ao destacar indicativos da emergência de uma nova história, dentre eles: a mistura de filosofias resultante dos progressos da informação e a reconstrução e sobrevivência das relações locais, as quais são intensificadas pela produção de uma população que se aglomera em áreas progressivamente menores.

Posto que objetivamos atuar sobre "o mundo como é" a partir da ótica do "mundo como pode ser", é de fundamental importância conhecê-lo - para isso, superando, inclusive, 
as crenças que nos são exaustivamente apresentadas. Como considerado por Carlos (2007, p. 11), "repensar a relação entre o local e o mundial torna-se, portanto, tarefa fundamental para entender o mundo moderno", e é em meio a esse quadro que está nosso presente esforço.

A temática ambiental, por sua vez, é de caráter complexo, sempre transitando entre o local e o global (VIEZZER; OVALLES, 1994). Logo, as reflexões sobre os problemas ambientais, necessariamente, se articulam àquelas referentes à globalização.

Ponderamos, também, que uma das possibilidades de enfrentamento da crise ambiental é a EA, como apontado por Carvalho (2006). Para tal, sua prática deve ser contínua e transcender propostas simplistas - como a de transmissão de conhecimento científico -, além de colaborar com a criação de uma relação justa e sustentável entre sociedade-sociedade e sociedade-natureza, desde as formas mais individuais e locais em que essa relação se manifesta, até as mais coletivas e globais.

Leff (2001) esclarece que a EA não possui apenas um discurso único, havendo, pois, propostas que vão desde um neoliberalismo econômico até a construção de uma nova racionalidade produtiva. Assim, "cada uma destas perspectivas implica em projetos diferenciados de educação ambiental” (LEFF, 2001, p. 123).

Consideramos apropriada a proposta de Carvalho (2006), ao afirmar que o trabalho com a EA precisa contemplar as três dimensões esquematizadas na Figura 1.

Figura 1. As três dimensões que o trabalho com a EA deve abarcar

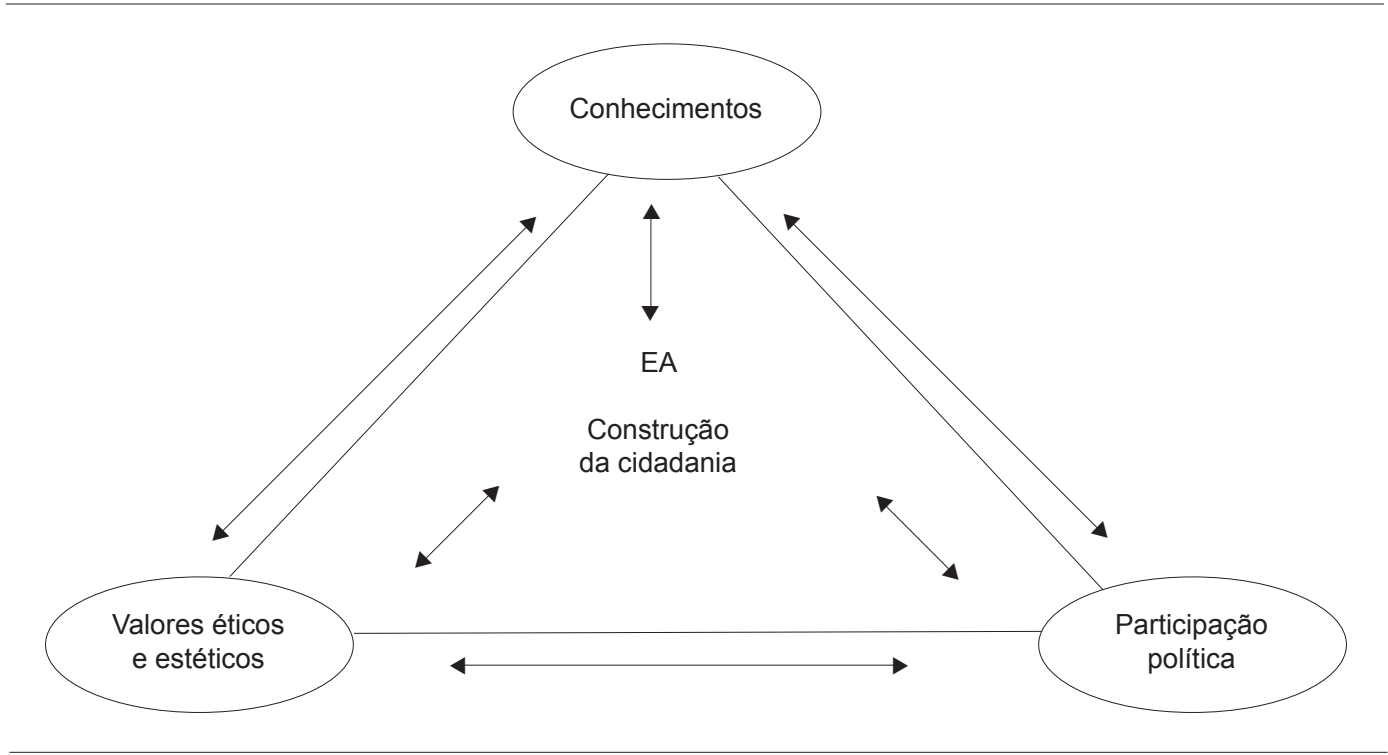

Fonte: Adaptado de Carvalho (2006).

Carvalho (1999) explicita que o trabalho com os conhecimentos vincula-se aos componentes e processos da natureza e à compreensão das complexas interações estabelecidas entre o homem e a natureza. A dimensão valorativa, por sua vez, corresponde à tentativa de 
compreender e buscar novos padrões coletivos de relação sociedade-natureza. E, por fim, a terceira dimensão está atrelada ao desenvolvimento da capacidade de participação política do indivíduo rumo à construção da cidadania e da democracia.

Refletindo, ainda, sobre a necessidade de práticas menos simplistas, chamou-nos a atenção a questão das escalas local e global na EA. Uma das pistas para se pensar sobre essa questão veio do Tratado de Educação Ambiental para Sociedades Sustentáveis e Responsabilidade Global, que foi aprovado durante a RIO-92 por educadores e ambientalistas (VIEZZER; OVALLES, 1994). Neste tratado, dentro do plano de ações, a preocupação com esse assunto aparece junto à proposta de "trabalhar os princípios deste Tratado a partir das realidades locais, estabelecendo as devidas conexões com a realidade planetária, objetivando a conscientização para a transformação" (VIEZZER; OVALLES, 1994, p. 32).

Layrargues (2001, p. 133) reafirma a diretriz supracitada do tratado, ao defender que a EA deve partir da resolução de problemas ambientais locais, pois esta é a "melhor oportunidade tanto de enfrentamento dos problemas ambientais, como da compreensão da complexa interação dos aspectos ecológicos com os político-econômicos e socioculturais da questão ambiental". Assim, o trabalho com o local corresponderia, para o autor, um ponto de partida nas práticas de EA.

Além disso, o autor propõe que as práticas educativas de EA, focadas na resolução de problemas locais, não devem ser transformadas em atividades fins, com a perda da compreensão mais abrangente/global da problemática que as envolve. Deste modo, os problemas ambientais devem ser temas geradores que problematizem a realidade para compreendê-la de uma forma mais profunda, instrumentalizando para uma ação crítica de sujeitos em processo de conscientização.

O slogan "Pensar globalmente. Agir localmente.", que tem circulado na EA há cerca de três décadas, foi criado em 1972, durante a United Nations Conference on the Human Environment, ocorrida em Estocolmo, passando, então, a integrar a, até então válida, International Environmental Education Programme. De acordo com Noel (2002), apesar desta publicidade, os educadores ambientais não necessariamente puseram o slogan em prática, sendo que as questões ambientais locais são mais efetivamente contempladas do que as globais, que costumam ser trabalhadas de modo equivocado e problemático.

Até a metade da década de 1980, "pensar globalmente, agir localmente" era um axioma da EA, uma verdade que não necessitava de validação de um especialista. Porém, críticas foram feitas a esse respeito, posto que, para alguns pesquisadores, este slogan cultiva o discurso neocolonialista na EA, por privilegiar, sistematicamente, os interesses e perspectivas do Ocidente, em especial dos Estados Unidos da América (NOEL, 2002). Considerando a complexidade das relações que se estabelecem entre o local e o global, julgamos que o slogan "pensar e agir local e globalmente" seja mais apropriado para essa questão.

Ao pensarmos sobre as possibilidades de problematização das escalas local e global na temática ambiental, indicamos que é apropriado considerarmos que, embora em um primeiro momento, o local pareça mais familiar aos educandos, a interdependência entre estas escalas já não nos permite afirmar que determinado aspecto é completamente local, sob pena de sermos reducionistas e simplistas.

Portanto, temos que o global pode ser igualmente familiar aos mesmos, o que não torna indispensável os esforços do educador ambiental para problematizar a complexidade das 
articulações que se estabelecem local e globalmente. Além disso, o global, em determinadas situações, pode despertar tanto ou mais interesse nos educandos que o local, como, por exemplo, a discussão atual sobre o aquecimento global. Assim, definir se a atividade deve partir de uma situação que se sobressai no local ou no global é uma escolha que os educadores devem tomar, levando em consideração o contexto e os atravessamentos da sua prática, despontando como primordial a devida articulação entre esses dois aspectos durante o desenvolvimento do trabalho.

Em um mundo onde as relações sociais, políticas e econômicas são intensas, onde o local e o global coexistem pacificamente ou não, torna-se fundamental efetivar o slogan "pensar e agir local e globalmente" nos processos educativos. Trabalhar coerentemente com a EA exige a abordagem

[...] de um conhecimento necessário para que os alunos adquiram uma base adequada da compreensão essencial do meio ambiente global e local, da interdependência dos problemas e soluções e da importância da responsabilidade de cada um para construir uma sociedade planetária mais equitativa e ambientalmente sustentável. (JACOBI, 2003, p. 204)

Isso não é uma tarefa simples, visto que melhorar a compreensão sobre as relações estabelecidas nos fenômenos e processos entre o global e o local é um dos grandes desafios postos às ciências da nossa época (WILKANKS; KATES, 1999). Sendo assim, este é um debate recente com o qual acreditamos que a EA deva contribuir, dentre outras coisas, por meio do caráter unificador da temática ambiental que, dada sua complexidade, exige um diálogo entre os diversos saberes, inclusive, os construídos pelas ciências.

\section{A pesquisa}

Diante da problemática anunciada, objetivamos mapear e discutir a produção acadêmica referente às escalas local e global encontradas em trabalhos de EA, a partir de teses e dissertações constantes no Banco de Teses da Coordenação de Aperfeiçoamento de Pessoal de Nível Superior (CAPES), fonte representativa de acesso à produção acadêmica brasileira. Ademais, buscamos identificar aspectos significativos referentes a essas escalas nessa produção.

A pesquisa realizada foi do tipo "estado da arte". Esta é de caráter bibliográfico e implica o desafio de mapear e de discutir determinada produção acadêmica em diferentes campos do conhecimento, com o objetivo de identificar quais aspectos e escalas vêm sendo destacados e privilegiados em diferentes épocas e lugares, bem como reconhecer de que formas e em que condições estes trabalhos têm sido produzidos (FERREIRA, 2002).

O levantamento das teses e dissertações, que constituíram nosso corpus documental, foi realizado a partir da inserção do termo "educação ambiental" no campo de busca "Assunto" do Banco de Teses Capes ${ }^{2}$. Convém esclarecer que a ferramenta em questão divulga dissertações e

\footnotetext{
${ }^{2}$ Disponível em: <http://www.capes.gov.br/servicos/banco-de-teses>. Acesso em: 03 jun. 2014.
} 
teses brasileiras, produzidas a partir de 1987, fornecendo, para isto, o resumo de cada trabalho, além dos dados institucionais vinculados ao mesmo.

No intento de garantir a representatividade do corpus documental, selecionamos $10 \%$ do total dos trabalhos acadêmicos resultantes da busca (realizada em fevereiro de 2010), respeitando, para tal, a ordem alfabética dos nomes dos autores. Os 260 trabalhos selecionados foram reunidos em um aplicativo Word®.

A leitura flutuante desses 260 resumos levou à identificação de uma grande variedade de termos que faziam referência, direta ou não, às escalas local e global, conforme discutiremos mais à frente. Tal variedade tornou inviável o emprego destes termos como palavras-chave para delimitar, em uma segunda etapa do levantamento, o corpus documental definitivo.

Frente a esta dificuldade, optamos por definir o corpus a partir de uma nova leitura dos 260 resumos identificados nesse momento da pesquisa, selecionando aqueles que mencionavam, mesmo que indiretamente, um ou mais dos aspectos do nosso recorte de pesquisa (local e/ou global), o que correspondeu a 54 trabalhos.

Após definição do nosso corpus documental, a investigação prosseguiu a partir da análise de aspectos (descritores), propostos por uma ficha catalográfica elaborada conjuntamente por pesquisadores da Unicamp, Unesp (campus de Rio Claro), USP e UFSCar . A saber, os descritores utilizados foram: dados bibliográficos e institucionais do trabalho, nível de ensino ao qual o trabalho está direcionado, área de conhecimento ao qual o trabalho faz referência, foco temático, tema ambiental e palavras-chave.

As 54 fichas catalográficas preenchidas foram, posteriormente, assentadas no aplicativo Acess ${ }^{\circledR}$, o qual, juntamente com o Excel ${ }^{\circledR}$, permitiu a sistematização dos descritores por meio da elaboração de gráficos e tabelas.

No intento de explorar as referências específicas dos resumos sobre as escalas local e global, adotou-se a técnica de análise de conteúdo dos mesmos. Esta técnica é caracterizada como a investigação da simbologia das mensagens, exigindo, assim, leitura e releitura dos dados para construir e registrar categorias e tipologias presentes na unidade de análise, a partir das quais se interpretam os dados coletados (ANDRÉ, 2005; LÜDKE; ANDRÉ, 1986).

Desse modo, realizamos, inicialmente, leituras flutuantes de todo o material coletado, no intento de nos familiarizarmos com o mesmo. Prosseguimos com leituras cuidadosas e exaustivas, atreladas a uma tentativa inicial de sistematização do conteúdo a partir do nosso recorte de pesquisa. As subcategorias, por despontarem mais diretamente a partir dos trabalhos analisados, foram primeiramente identificadas. A análise do conjunto das subcategorias permitiu o agrupamento das mesmas em três categorias (local/regional, global e local-global). Por fim, a análise das categorias e das subcategorias possibilitou o estabelecimento de um diálogo entre os dados coletados e a literatura, na tentativa de identificar aspectos significativos referentes a essas escalas nas teses e dissertações de EA brasileiras.

\footnotetext{
${ }^{3}$ Trata-se do projeto de pesquisa "A educação ambiental no Brasil: análise da produção acadêmica - teses e dissertações", que está sendo desenvolvido por pesquisadores dessas quatro universidades (CNPQ - N. 480328/2010-2).
} 


\section{Resultados e discussão}

\section{a) Resumos: uma história possível}

Identificamos uma grande diversidade de termos utilizados para se referir ao local e ao global, indicando talvez que essa é uma discussão teórica na EA ainda muito inicial e dispersa em termos de referencial teórico. Dos 54 trabalhos analisados, notou-se que 21 deles apresentam a palavra local (is) em seus resumos, 12 fazem referências a aspectos globais, porém apenas um usa o termo "globais". Os demais se valem dos termos: planeta/planetária (seis), mundo (três), Terra (dois), globalização (dois), multinacionais (um) e terrestres (um). Além destas palavras que detinham relação mais direta com o nosso recorte investigativo, foi possível reconhecer que os termos como comunidade, entorno, região, cotidiano, lugar, cidade e município foram comumente empregados em nosso corpus documental e, no geral, indicavam estabelecer relação com a dimensão local da temática ambiental.

Outro ponto interessante, possibilitado pela nossa compreensão dos resumos tese/ dissertação, consiste na identificação do uso intercambiável de palavras distintas ao longo do texto, sem maiores distinções entre elas, como por exemplo: realidade local = realidade próxima do aluno (trabalho $1-\mathrm{T} 1$ ); condições socioambientais locais = realidade a que pertencem (T2); questões ambientais locais $=$ questões do cotidiano $=$ sociedade em que vivem (trabalho 3); condições socioambientais do município = mundo vivido (T29); vida no Planeta = mundo em que vivem (T33). Destacamos, ainda, que os últimos dois exemplos apresentados indicam, claramente, que termos similares (mundo vivido e mundo em que vivem) podem fazer referência a diferentes escalas, respectivamente, local e global, de acordo com o contexto do resumo tese/dissertação.

A interpretação de que vocábulos similares podem remeter a escalas diferenciadas é reafirmada quando analisamos a que limites geográficos o termo local é vinculado: emprego da palavra local referindo-se a um país africano - Moçambique - (T1), condições socioambientais locais referindo-se ao bairro (T2), e localidade referindo-se ao município (T18). No T16, nota-se que os termos são utilizados sem clara distinção para fazer referência às localidades circunvizinhas de uma estação ecológica, o mesmo ocorre no T9 que se remete à comunidade do entorno do parque municipal. Contudo, o mesmo não é observado no T21 que, ao empregar os termos local e regional seguidos um do outro, indica não se tratar da mesma dimensão, porém maiores explanações não são feitas a respeito desta distinção. Ainda frente à heterogeneidade do emprego dos termos local e regional, temos que o T7 alude ao litoral norte do estado do Paraná, atrelando-o à dimensão local, enquanto o T26, ao se referir ao sul do estado de Roraima, fala em região.

Esta observação evidencia quanto a escala - entendida como qualquer nível geográfico ou temporário no qual um fenômeno é reconhecido - é socialmente definida, em particular, por certos aspectos políticos, científicos, legais ou culturais (CASH; MOSER, 2000). Ela é mutável e suscetível a adaptações para melhor atender o gerenciamento do problema ambiental posto, como lembram Cash e Moser (2000), sendo comum as pessoas adotarem uma definição de escala para um problema específico e para fins particulares. Portanto a definição de qualquer escala é raramente congruente. Frente a estas reflexões, optamos por agrupar as referências ao local e regional como similares e, a partir de então, utilizaremos a expressão local/regional. 
O contato inicial com o corpus documental permitiu reconhecer que, embora a CAPES padronize as informações que devem ser fornecidas durante o preenchimento da ficha para divulgação das dissertações e teses, existe discrepância entre os resumos disponibilizados, no que diz respeito a sua estrutura. Araújo (1999, p. 26) sinaliza que apesar do resumo ser um gênero textual frequentemente utilizado pela comunidade científica, "dado seu valor e função em reunir e apresentar informações básicas, de maneira concisa, coerente e seletiva”, os manuais de redação pouco auxiliam os pesquisadores em sua escrita, o que pode justificar, pelo menos em parte, a heterogeneidade observada nesta pesquisa.

De fato, uma das discussões recorrentes sobre a pesquisa tipo "estado da arte" remete-se à validade do uso de resumos como corpus documental. Ao refletir sobre esta questão, Ferreira (2002), ancorando-se em Bakhtin (1997 apud FERREIRA, 2002, p. 267), sugere que cada resumo pode ser lido como um dos gêneros do discurso ligados à esfera acadêmica, com finalidade e condições específicas de produção, que conta certa realidade desta produção e, assim, haverá tantas histórias sobre a produção acadêmica quantos resumos (de uma mesma pesquisa) forem encontrados, sendo que uma palavra excluída, substituída ou acrescentada a qualquer um dos resumos pode permitir que cada leitor faça uma apropriação diferente daquele texto.

Conforme destaca Ferreira (2002, p. 269), "um pesquisador jamais terá controle sobre seu objeto de investigação ao tentar delimitar seu corpus para escrever a história de determinada produção". Deste modo, é superficial pensar que o pesquisador, ao considerar apenas os resumos, estará escrevendo a história da produção acadêmica sobre certa área em um país; ele estará, no máximo, escrevendo uma das histórias possíveis de serem construídas a partir da interpretação destes resumos.

No presente trabalho, aceitamos as afirmações e considerações feitas por Ferreira (2002), o que exige que, ao lidarmos com nosso objeto de leitura e análise, os resumos, não entendamos que os mesmos estabeleçam com a pesquisa uma relação metonímica, nem uma relação de fidedignidade em relação à pesquisa que o origina e, nem tão pouco, uma relação exclusivamente de contiguidade. Assim, os resumos foram lidos e analisados enquanto uma "realidade relativamente independente, produto de uma tensão construída na continuidade e na ruptura com o trabalho que lhe dá origem, numa relação dialética entre os gêneros, entre as condições de sua produção e práticas discursivas” (FERREIRA, 2002, p. 270).

\section{b) Análise dos descritores}

Os 54 resumos de teses e dissertações disponibilizados pela CAPES que constituíram o nosso corpus documental apresentam grande heterogeneidade em relação ao conteúdo abordado. Apesar disto, consideramos que eles nos permitiram contar uma das muitas histórias possíveis a respeito da presença das escalas local-global nas práticas de EA. Porém, alguns dados, como os institucionais, área de conhecimento/curricular e contexto educacional, aqui chamados de descritores, permitiram uma análise mais objetiva.

Observamos que houve um aumento considerável dos trabalhos entre os anos de 2001 e 2002, período após o qual apenas pequenas oscilações são observadas. Cumpre salientar que, embora não tenhamos restringido nosso levantamento de teses e dissertações a um determinado momento, obtivemos trabalhos pertinentes ao nosso foco de pesquisa apenas a partir do ano de 1995, e não de 1987, como seria esperado. Entretanto, isto não nos permite afirmar que não 
exista algum resumo que aborde as dimensões local e global em trabalhos de EA anteriores ao ano de 1995, dado que os trabalhos selecionados não contemplaram as 2.600 teses e dissertações constantes no banco na data de levantamento destes.

Uma diversidade de instituições, programas e orientadores estão relacionados a estes trabalhos, sendo que as universidades públicas destacaram-se pelo número de teses e dissertações produzidas. Estes dados reforçam a constatação de que, no Brasil, a produção acadêmica e científica sobre a temática é realizada em diferentes Instituições de Ensino Superior (IES), dentro dos mais diversos programas de pós-graduação vinculados às distintas áreas de conhecimento (FRACALANZA, 2004). Convém detalhar, porém, que apesar da diversidade de programas de pós-graduação identificados (26 no total), a maioria deles está vinculada à área de educação (24\% Programas de Educação, e 11\% Programas de EA).

Notamos que $67 \%$ da produção foi desenvolvida nas regiões sudeste e sul, sendo $41 \%$ dos trabalhos defendidos no estado de São Paulo. Importante destacar que dez estados brasileiros, todos concentrados nas regiões norte e nordeste, não tiveram representatividade na produção acadêmica analisada. É possível identificar, com isso, disparidades regionais significativas na distribuição dos programas e cursos avaliados, também observadas por Sousa e Bianchetti (2007) ao estudarem os rumos das pesquisas e dos programas de pós-graduação em educação no Brasil. É conveniente, porém, atentar que, apesar das regiões sudeste e sul serem bastante populosas, a região nordeste é a segunda mais populosa do país, o que nos permite inferir que estamos diante de oportunidades desiguais de formação e produção de conhecimento (SOUZA; BIANCHETTI, 2007), provavelmente atreladas a fatores políticos e econômicos.

A grande maioria dos trabalhos foi realizada para a obtenção do título de mestre, o que acreditamos estar especialmente vinculado a problemas de financiamento na área da educação, à qual a maioria pertence. Sousa e Bianchetti (2007) nos ajudam a refletir sobre essa questão, ao apontarem que, na área da educação, é cada vez maior o número de pós-graduandos trabalhadores, o que pode afetar, negativamente, as condições desses alunos-trabalhadores em relação às exigências da pós-graduação, comprometendo, inclusive, a continuidade dos seus estudos.

Os trabalhos analisados confirmam uma tendência já detectada em pesquisas de EA, que, frequentemente, não se atrelam a uma área específica do conhecimento ou do currículo; abordagem a qual nos parece condizente com a complexidade dessa temática. No entanto, convém ressaltar que, embora a Geografia seja a área de conhecimento/curricular que mais se aproxima da temática local-global, identificamos um único trabalho dessa área voltado à EA e as escalas local e global. Isto sinaliza uma lacuna a ser preenchida na interface entre produção de conhecimento em geografia e em EA.

O contexto educacional mais referenciado na produção acadêmica investigada foi o contexto escolar, com 59\% de representação no total de trabalhos estudados. Chama-nos a atenção, porém, o fato de o contexto não escolar ter sido contemplado em $50 \%$ dos resumos selecionados, algo similar ao observado por Freitas e Oliveira (2006). Estes autores reconheceram uma tendência de os trabalhos de EA utilizarem diversos espaços sociais como espaços formativos, para além da escola. Em meio a isso, Reigota (2007) constatou ainda, ao investigar teses e dissertações brasileiras, que a EA está voltada para vários grupos sociais, sendo que, em nosso trabalho, encontramos dados que apoiam esta verificação.

Acreditamos que o trabalho de EA com as escalas local e global, em especial a local, favoreça tal tendência, posto que, como observado em várias teses e dissertações, com a finalidade 
de lidar com interesses ou problemas locais/regionais, uma estratégia comumente vislumbrada é a EA não formal, envolvendo uma dada comunidade, para se compreender, valorizar e/ou atuar frente a realidade posta, rumo à almejada. Ressaltamos as possibilidades e a riqueza de a EA voltar-se, a partir da escola, à comunidade do entorno.

Em nosso corpus documental, reconhecemos uma grande variedade de temas ambientais abarcados, sendo que a questão do lixo/resíduos sólidos, assim como o tema ecossistema/ bioma foram privilegiados, embora juntos somem apenas $22 \%$ do total. Salientamos ainda que o tema ecossistema/bioma atrelou-se, sobretudo, ao trabalho com aspectos locais, envolvendo a tentativa de proporcionar, aos alunos e/ou visitantes de parques, conhecimento, valorização e/ou atuação local. Com isso, este tema desponta como uma possibilidade de trabalhar EA localmente, ainda que ressaltemos a necessidade de que aspectos globais igualmente sejam abarcados de modo articulado a este trabalho.

Em meio aos diversos focos de investigação identificados, o foco privilegiado, com representatividade de $35 \%$, foi “Currículos, programas e projetos", em uma perceptível tentativa de propor intervenções (programas e projetos) em um local ou, ainda, de analisar se projetos e programas de EA postos em prática influenciaram ou não localmente.

\section{c) Análise de conteúdo}

$\mathrm{Na}$ segunda etapa da análise do nosso corpus documental, objetivamos inventariar esta produção, por meio da identificação de tendências, ênfases, aproximações ou distanciamentos dos trabalhos entre si. Assim, nossa meta foi buscar responder questões referentes a "o quê" e "o como" desses trabalhos, como exposto a seguir.

Como é possível constatar no Quadro 1, a maioria dos resumos (33 trabalhos) que faz referência ao nosso recorte de pesquisa traz referências a aspectos da dimensão local; e, dentro desta, voltam-se para a prática da EA como forma de atuar localmente, seja propondo práticas, em alguns casos, que procedem a um diagnóstico dos problemas/interesses locais, ou, ainda, avaliando se tal prática influencia o local, e como isto é efetivado. Alguns trabalhos voltam-se para aspectos da dimensão local no trabalho docente. Enquanto dois destes identificam que professores reconhecem, trabalham e valorizam aspectos locais, outros focam a formação de professores para trabalharem com questões locais. Noel (2002) explicita essa tendência aqui constatada, ao identificar que muitos educadores incorporam questões locais em programas de EA, geralmente de modo efetivo, porém há poucas evidências sobre trabalhos bem-sucedidos com a dimensão global.

Como já mencionado, o termo "comunidade", bem como "entorno" e "cotidiano", foi recorrentemente associado ao trabalho com o local. Em relação ao termo comunidade, este apareceu em uma grande porcentagem dos trabalhos (11 trabalhos) e, comumente, está associado a uma busca em envolver a comunidade com interesses/problemas locais, seja por intermédio do conhecimento dos mesmos, por meio da atuação frente às questões locais, do trabalho com a dimensão valorativa (valorização local/regional; estabelecer vínculos de pertencimento com o meio) ou, ainda, contemplando as duas ou mais dimensões do trabalho com EA, propostas por Carvalho (2006). Dois trabalhos ainda foram especificamente voltados à tentativa de construir espaços de aprendizagem comunitária: estes foram enquadrados na categoria local, por entendermos que a busca por estes espaços corresponde a tentativas de lidar e fortalecer o local. 
Quadro 1. Distribuição das 54 teses e dissertações analisadas, constantes no Banco de Teses da Capes, por categorias e subcategorias referentes às escalas local/regional e global

\begin{tabular}{|c|c|c|c|}
\hline Categorias & Subcategorias & $\begin{array}{l}\text { Referência do } \\
\text { trabalho }\end{array}$ & $\begin{array}{l}\text { Porcentagem } \\
\text { aproximada }\end{array}$ \\
\hline \multirow{8}{*}{$\begin{array}{l}\text { Local/ } \\
\text { Regional }\end{array}$} & $\begin{array}{l}\text { Estudos que investigam a possibilidade de propor ou } \\
\text { propõem EA para o trabalho com aspectos locais }\end{array}$ & $\begin{array}{l}7,8,11,21,27,5 \\
10,17,32,34,36 \\
38,39,46,50,51\end{array}$ & $30 \%$ \\
\hline & $\begin{array}{l}\text { Estudos que analisam a percepção de diferentes } \\
\text { públicos a respeito de aspectos locais }\end{array}$ & 14,25 & $4 \%$ \\
\hline & $\begin{array}{l}\text { Estudos que apresentaram como dados o fato de os } \\
\text { professores reconhecerem / trabalharem / valorizarem } \\
\text { a esfera local }\end{array}$ & 15,16 & $4 \%$ \\
\hline & $\begin{array}{l}\text { Estudos que primeiro diagnosticam aspectos } \\
\text { referentes ao local/regional para, em seguida, } \\
\text { proporem atividades de EA }\end{array}$ & $18,26,40$ & $5,5 \%$ \\
\hline & $\begin{array}{l}\text { Estudo voltado à formação docente para o estudo } \\
\text { com local }\end{array}$ & 49 & $2 \%$ \\
\hline & $\begin{array}{l}\text { Estudos que propõem atividades de EA para } \\
\text { identificar espaços de aprendizagem comunitária }\end{array}$ & 19,43 & $4 \%$ \\
\hline & $\begin{array}{l}\text { Estudo que analisa a inserção da paisagem local pela } \\
\text { comunidade }\end{array}$ & 20 & $2 \%$ \\
\hline & $\begin{array}{l}\text { Estudos que analisam o trabalho ou a influência de } \\
\text { projetos de EA no local }\end{array}$ & $23,28,44,54$ & $7 \%$ \\
\hline Global & $\begin{array}{l}\text { Estudos que propõem atividades de EA para reforçar } \\
\text { vínculos com o local/regional }\end{array}$ & 2,43 & $4 \%$ \\
\hline \multirow{6}{*}{ Local-Global } & $\begin{array}{l}\text { Estudo que vislumbra/propõe EA para (enfrentar) } \\
\text { problemas globais }\end{array}$ & $35,42,45,53$ & $7 \%$ \\
\hline & $\begin{array}{l}\text { Estudos que apontam que a prática de EA teve reflexo } \\
\text { nas escalas local e global }\end{array}$ & $22,30,31,33$ & $7 \%$ \\
\hline & $\begin{array}{l}\text { Estudo que identifica que participantes de um } \\
\text { movimento social reconhecem a dimensão global }\end{array}$ & 6 & $2 \%$ \\
\hline & $\begin{array}{l}\text { Estudos que mencionam/discutem o trabalho com EA } \\
\text { em diferentes escalas de mundo }\end{array}$ & $1,29,48$ & $5,5 \%$ \\
\hline & $\begin{array}{l}\text { Estudos que trabalham aspectos locais e inferem que } \\
\text { estes refletem na escala global }\end{array}$ & $2,3,47,52$ & $7 \%$ \\
\hline & $\begin{array}{l}\text { Estudos que mencionam aspectos globais ao focarem } \\
\text { atuação no local/regional }\end{array}$ & $37,4,9,13,31$ & $9 \%$ \\
\hline
\end{tabular}

Fonte: Banco de teses da Capes. 
Em conjunto, esse grande número de trabalhos reafirma a possibilidade de resolução de problemas ambientais na dimensão local, por meio da valorização do pensamento local e de soluções a serem buscadas nessa dimensão. Embora estes trabalhos se coadunem com uma perspectiva que tem sua validade reconhecida por autores como Santos (2002) e Porto-Gonçalves (2007), é importante ressaltar que eles deixam lacunas que comprometem a articulação entre as escalas local e global, o que, como já mencionado, pode prejudicar os rumos do enfrentamento dos problemas ambientais como um todo, no local e no global.

A questão do desenvolvimento local, mencionada em vários trabalhos diretamente e indiretamente identificada em tantos outros, é estudada por Martins (2002), que considera o desenvolvimento local um produto da iniciativa compartilhada, da inovação e do empreendedorismo comunitário, sendo que sua origem vincula-se ao contexto, no que se esgotam as concepções de desenvolvimento associadas ao progresso material (acúmulo de riquezas), pessoal ("ganhar a vida") e ilimitado ("quanto mais melhor"). O diferencial do desenvolvimento local não são seus objetivos (bem-estar, qualidade de vida, endogenia, sinergias etc.), mas sua proposta de rever a questão da participação, dado que atribui e assegura à comunidade o papel de agente, e não apenas de beneficiária desse desenvolvimento.

Portanto, a formação de um senso crítico e a sensibilidade, e não apenas a tomada de consciência, estão na essência da participação pessoal. O autor reconhece que, de fato, esses requisitos são de difícil obtenção, ainda mais quando não estimulados por períodos de pouca democracia. Cumpre acrescentar que, a nosso ver, tal proposta aponta para a importância do trabalho com valores e com a dimensão política, ao requisitar uma formação que contemple a sensibilidade, o senso crítico e a participação pessoal.

Em relação aos trabalhos voltados ao contexto da educação formal que propuseram intervenção concreta no local, estes se aproximaram da proposta de Martins (2002), para o qual a ação na escola local, bem como toda reflexão e investigação, devem atuar sobre problemas importantes e concretos de uma comunidade em seu entorno ou lugar; considerando, entretanto, que não sejam ignoradas as múltiplas determinações e interações com outras escalas ou níveis de análise.

Kincheloe (1997 apud COMPIANI, 2007, p. 33) ao abordar este assunto, acrescenta que o entendimento do local, ao focar o particular, baseia-se em um entendimento maior do entorno e dos processos que o moldam. Desta maneira, o sentido do local melhora o entendimento do contexto, do singular e do histórico, resultando em uma compreensão aguçada do abstrato, das propriedades, do generalizável. Nesse sentido, para esses autores, iniciar o trabalho com a temática ambiental a partir de aspectos locais desponta como uma possibilidade de expandir para questões globais e articular essas escalas.

Reiteramos, todavia, que, embora em um primeiro momento, o local pareça mais apelativo para os alunos, dada sua concretude, é necessário levarmos em conta, também, que tanto aspectos locais quando globais, mesmo que difusamente, são comumente abordados na mídia, podendo despertar, igualmente, o interesse dos educandos e servir como ponto de partida para o trabalho com a temática ambiental. Logo, iniciar o trabalho com a dimensão local não desponta, a nosso ver, como uma regra, mas como uma relevante possibilidade. E a regra que deve existir, segundo nosso entendimento, é a da articulação entre as escalas local e global.

Em nosso corpus documental, quatro resumos fizeram referências apenas à dimensão global, dois deles vislumbrando que a EA deve contribuir com o global, e os demais, propondo 
atividades de EA pautadas no contexto global, no intento de enfrentar aspectos negativos do processo de globalização.

Estes trabalhos parecem ir ao encontro das ideias de Santos (2002). O autor explicita que a crença na irreversibilidade do processo e das formas atuais da globalização está associada com a força com que o fenômeno se revela e se instala em todos os lugares e em todas as esferas da vida, levando a pensar que não existem alternativas para o presente estado da globalização. O autor discute, porém, que, para superar essa confusão do que já foi realizado e o que pode ser realizado, deve-se considerar que o mundo é formado não apenas pelo que já existe, mas, também, pelo que pode efetivamente existir. Assim, nas palavras de Santos (2002, p. 160): “o mundo datado de hoje deve ser enxergado como o que na verdade ele nos traz, isto é, um conjunto presente de possibilidades reais, concretas, todas factíveis sob determinadas condições”. Dezessete trabalhos fizeram menção aos aspectos locais e globais, entretanto apenas dois destes objetivavam olhar para possíveis articulações entre estas escalas. Os demais trouxeram apenas referências nos mais diversos locais do resumo, como na introdução apresentada, nos resultados e/ou nas considerações finais. A maioria destes resumos menciona questões globais em sua introdução e traze como objetivo atuar no local; outros, ao desenvolverem propostas de EA localmente, concluem que tal prática refletiu no global ao influenciar os alunos a valorizarem/ respeitarem o planeta ou, ainda, afetaram positivamente, tanto na dimensão local como na global. Um único trabalho, ao analisar a percepção de participantes de um movimento social, identifica que estes reconhecem aspectos do global ao refletirem a respeito da questão ambiental.

Cumpre salientar que, partindo da perspectiva de que a globalização faz com que as atividades cotidianas sejam afetadas por ocorrências que se passam do outro lado do mundo, ao mesmo tempo em que os hábitos locais têm consequências globais (GIDDENS, 1994), o local e global passam a conviver diária e intrinsecamente nas sociedades atuais (GASKELL; OGAWA, 2004). Desta forma, entendemos que, mesmo os trabalhos que fazem referência a uma única dimensão, inerentemente podem trazer contribuições para ambas, dado o imbricamento entre elas, que, de longe, supera uma possível compreensão dicotômica do fenômeno. Porém, consideramos que a articulação entre local e global deve ser explicitamente contemplada nos trabalhos.

Em relação aos três resumos que mencionam o trabalho da EA em diferentes escalas de mundo, dois deles objetivam discutir, de fato, esta questão. Um destes apresenta como objetivo trabalhar em sala de aula a EA em diferentes escalas de mundo, enquanto o outro se propõe a discutir o privilégio que as diretrizes educacionais em Moçambique, país de origem do autor, atribuem aos aspectos globais da EA em detrimento dos locais. Por fim, o terceiro destes textos não tem como foco discutir relações locais e globais, mas foi selecionado por apresentar, em seu resumo, que os livros didáticos e os Parâmetros Curriculares Nacionais (PCN), focos de análise do pesquisador, privilegiam problemas ambientais distantes/globais em detrimento dos locais, o que o autor julga como desinteressante e, mesmo, desmotivador para trabalhar EA com os alunos.

Convém sinalizar que as práticas de EA que abordam problemas ambientais distantes podem ser atrativas para os alunos, despontando como uma possibilidade de contemplar as escalas local e global em sala de aula. Isto porque, a partir deste interesse, o professor, junto aos estudantes, pode trabalhar na identificação de aspectos comuns e de peculiaridades de diferentes locais (por exemplo, comparar o local/realidade desse aluno com a realidade do outro local pelo qual ele mostrou interesse), o que, em conjunto, pode permitir o reconhecimento de 
aspectos mais gerais/globais. Em função desse reconhecimento, o professor poderá estabelecer articulações entre ambas as escalas, buscando esclarecer, dentre outras coisas, como o global exerce influência nos diferentes locais e como os locais retêm singularidades.

\section{Conclusão}

A análise dos resumos de teses e dissertações permite afirmar que os trabalhos selecionados tendem a lidar com aspectos da dimensão local (61\%), sem, na maioria das vezes, abordar questões mais gerais. Em suma, propõe atividades de EA para atuação local frente a algum interesse ou problema identificado. Embora identifiquemos nisso uma possibilidade de intervenção mais concreta diante da realidade posta, alertamos para a importância de articular intencionalmente as escalas local e global nos trabalhos em EA, sob o risco de alcançarmos resultados pontuais por demasia frente à complexidade dessa temática, quando não, obtermos respostas contrárias às almejadas. Isso poderia implicar uma EA voltada à resolução de problemas imediatos/próximos, perdendo-se o objetivo de formar o cidadão com conhecimento mais profundo da problemática da globalização em suas inter-relações local-global.

Apenas quatro resumos remeteram-se, exclusivamente, a aspectos globais, sendo que dois destes trabalhos propõem atividades de EA para lidar com o global, consistindo em uma tentativa de enfrentar os problemas vigentes. Reconhecemos sua importância no sentido de fazer frente à impressão comumente observada, na sociedade, de que o contexto social, político, econômico e cultural não é passível de ser transformado.

Embora um terço dos resumos acadêmicos investigados faça menção a ambas as escalas, observamos em apenas dois trabalhos a intenção de discutir possíveis articulações entre o local e o global, indicando, claramente, uma fluidez no trabalho com a articulação dessas escalas, o que consideramos inviabilizar ou dificultar a adoção de medidas efetivas para enfrentamento da crise ambiental vigente.

Por fim, sinalizamos a necessidade de mais estudos que contemplem essa questão posta, especialmente, relacionados com a temática ambiental e sua prática educativa.

\section{Referências}

ANDRÉ, M. E. D. A. Estudo de caso em pesquisa e avaliação educacional. Brasília: Líber, 2005.

ARAÚJO, A. D. Uma análise da organização discursiva de 'resumos' na área da educação. Revista do GELNE, Teresina, PI, v. 1, n. 1, p. 26-30, 1999. Disponível em: < http:/ /www.gelne.org.br/ RevistaGelne/arquivos/artigos/art_4f50617e99e834e589f88f92069cc441_184.pdf >. Acesso em: 05 mar. 2010.

BANCO de teses da Capes. Disponível em: < http://www.capes.gov.br/servicos/banco-de-teses>. Acesso em: 03 jun. 2014. 
BITAR, A. L. Pesquisa em educação ambiental: a atividade de campo em teses e dissertações. 2010. 170 f. Dissertação (Mestrado em Educação) - Departamento de Educação, Universidade Estadual Paulista, Rio Claro, 2010.

CARLOS, A. F. Al. O lugar no/do mundo. São Paulo: Labur, 2007.

CARVALHO, L. M. A temática ambiental e o processo educativo: dimensões e abordagens. In: CINQUETTI, H. S.; LOGAREZZI, A. (Org.). Consumo e resíduos: fundamentos para o trabalho educativo. São Carlos: EdUFSCAR, 2006. p. 19-41.

CARVALHO, L. M. Educação e o meio ambiente na escola fundamental: perspectivas e possibilidades. Projeto: revista de educação, São Paulo, v. 1, n. 1, p. 5-9, jul./dez. 1999.

CASH, D. W.; MOSER, S. C. Linking global and local scales: designing dynamic assessment and management processes. Global Environmental Change, Guildford, v. 10, n. 2, p. 109-120, 2000. Disponível em: <http://www.susannemoser.com/documents/Cash-Moser_GEC2000.pdf >. Acesso em: 12 fev. 2010.

COMPIANI, M. O lugar e as escalas e suas dimensões horizontal e vertical nos trabalhos práticos: implicações para o ensino de ciências e educação ambiental. Ciência \& Educação, Bauru, v. 13, n. 1, p. 29-45, 2007.

FERREIRA, N. S. A. As pesquisas denominadas "estado da arte". Educação \& Sociedade, Campinas, v. 23, n. 79, p. 257-272, 2002. Disponível em: <www.scielo.br/pdf/es/v23n79/10857.pdf>. Acesso em: 20 mar. 2010.

FRACALANZA, H. As pesquisas sobre educação ambiental no Brasil e as escolas: alguns comentários preliminares. In: TAGLIEBER, J. E.; GUERRA, A. F. S. (Org.). Pesquisa em educação ambiental: pensamentos e reflexões de pesquisadores em educação ambiental. Pelotas: Universitária: UFPel, 2004. p. 55-77.

FREITAS, D.; OLIVEIRA, H. T. Pesquisa em educação ambiental: um panorama de suas tendências metodológicas. Pesquisa em Educação Ambiental, São Carlos, v. 1, n. 1, p. 175-191, jul./dez. 2006.

GASKELL, J.; OGAWA, M. Globalization and localization: competing tendencies or inevitable companions? In: INTERNATIONAL ORGANIZATION FOR SCIENCE AND TECHNOLOGY EDUCATION SYMPOSIUM, 11., 2004, Lublin. Proceedings... Lublin: Maria Curie-Sklodowska University Press, 2004. p. 29-30.

GIDDENS, A. Admirável mundo novo: o novo contexto da política. Caderno CRH, Salvador, v. 7, n. 21, p. 9-28, 1994. Disponível em: <http://www.cadernocrh.ufba.br/viewarticle. php?id=314\&layout=abstract $>$. Acesso em: 18 ago. 2008.

GRÜN, M. Uma discussão sobre valores éticos em educação ambiental. Educação \& Realidade, Porto Alegre, v. 19, n. 2, p. 171-195, 1994.

JACOBI, P. R. Educação ambiental: o desafio da construção de um pensamento crítico, complexo e reflexivo. Educação e Pesquisa, São Paulo, v. 31, n. 2, p. 233-250, 2005.

JACOBI, P. Educação ambiental, cidadania e sustentabilidade. Cadernos de Pesquisa, São Paulo, n. 118, p. 189-206, 2003. Disponível em: <www.scielo.br/pdf/cp/n118/16834.pdf>. Acesso em: 07 abr. 2008.

LAYRARGUES, P. P. A resolução de problemas ambientais locais deve ser um tema-gerador ou a atividade-fim da educação ambiental? In: REIGOTA, M. (Org.). Verde cotidiano: o meio ambiente em discussão. 2. ed. Rio de Janeiro: DP\&A, 2001. p. 131-148. 
LEFF, E. Educação ambiental e desenvolvimento sustentável. In: REIGOTA, M. (Org.). Verde cotidiano: o meio ambiente em discussão. 2. ed. Rio de Janeiro: DP\&A, 2001. p. 111-129.

LÜDKE, M.; ANDRÉ, M. E. D. A. Pesquisa em educação: abordagens qualitativas. São Paulo: EPU, 1986.

MARTINS, S. R. O. Desenvolvimento local: questões conceituais e metodológicas. Interações, Campo Grande, v. 3, n. 5, p. 51-59, set. 2002. Disponível em: <www3.ucdb.br/mestrados/ RevistaInteracoes/n5_sergio_martins.pdf>. Acesso em: 22 jun. 2010.

MORIN, E. Os sete saberes necessários à educação do futuro. São Paulo: Cortez, 2001.

NOEL, G. Thinking/acting locally/globally: western science and environmental education in a global knowledge economy. International Journal of Science Education, Abingdon, v. 24, n. 11, p. 1217-1237, 2002.

PORTO-GONÇALVES, C. W. Educação, meio ambiente e globalização. In: CONGRESSO IBERO-AMERICANO DE EDUCAÇÃO AMBIENTAL, 5., 2006, Joinville. Anais... Rio de Janeiro: Associação Projeto Roda Viva, 2007. p. 15-27.

REIGOTA, M. O estado da arte da pesquisa em educação ambiental no Brasil. Pesquisa em Educação Ambiental, São Carlos, v. 2, n. 1, p. 33-66, 2007.

SANTOS, B. S. Um discurso sobre as ciências. Porto: Afrontamento, 1998.

SANTOS, M. Por uma outra globalização: do pensamento único a consciência universal. 9. ed. Rio de Janeiro: Record, 2002.

SOUZA, S. Z.; BIANCHETTI, L. Pós-graduação e pesquisa em educação no Brasil: o protagonismo da ANPEd. Revista Brasileira de Educação, Rio de Janeiro, v. 12, n. 36, p. 389-546, 2007.

Disponível em: <www.scielo.br/pdf/rbedu/v12n36/a02v1236.pdf>. Acesso em: 12 jul. 2010.

VIEZZER, M. L.; OVALLES, O. (Org.). Manual latino-americano de educ-ação ambiental. São Paulo: Gaia, 1994.

WILBANKS, T. J.; KATES, R. W. Global change in local places: how scale matters. Climatic Change, Dordrecht, n. 43, p. 601-628, 1999. Disponível em: <www.dvgu.ru/meteo/library/211857.pdf>.

Acesso em: 13 abr. 2010. 